\title{
Female Futsal Players’ Profile and Biochemical Alterations through Intermittent High-Intensity Exercise Training
}

\author{
Camila S. C. da Costa ${ }^{1}$, Alexandre Palma ${ }^{2}$, Cristiana M. Pedrosa ${ }^{1}$, Anna Paola T. R. Pierucci $^{{ }^{*}}$ \\ ${ }^{1}$ Departamento de Nutrição Básica e Experimental, Instituto de Nutrição Josué de Castro, Universidade Federal do Rio de Janeiro \\ (UFRJ), Cidade Universitária, Rio de Janeiro, Brazil; ${ }^{2}$ Universidade Federal do Rio de Janeiro (UFRJ), Escola de Educação Física e \\ Desportos, Rio de Janeiro, Brazil. \\ Email: "pierucci@nutricao.ufrj.br
}

Received September $14^{\text {th }}, 2011$; revised November $1^{\text {st }}, 2011$; accepted November $8^{\text {th }}, 2011$

\begin{abstract}
The aim of the study was to determine the physical, physiological and nutritionalcharacteristics of female futsal players and selected markers of oxidative stress after their exercise training (Loughborough Intermittent Shuttle Test). Eight health female futsal players (age $21.3 \pm 3.2$ years, body mass $64.5 \pm 5.6 \mathrm{~kg}$, height $169.5 \pm 6.5 \mathrm{~cm}$, body mass index $22.45 \pm 2.25 \mathrm{~kg} / \mathrm{m}^{2}$; mean $\pm \mathrm{SD}$ ) participated in this study. Blood samples were collected before, during and immediately after the exercise for glucose, lactate, ascorbic acid, total plasma antioxidant potential, lipid hydroperoxides, malondialdehyde and creatine kinase concentrations. Female futsal players appeared to meet caloric needs but failed to meet minimum carbohydrate and vitamin $\mathrm{A}, \mathrm{C}$ and $\mathrm{E}$ recommendations. Immediately after the exercise there were an increase in lipid hydroperoxides (ranging from $9.32 \pm 1.86 \mu \mathrm{mol} \cdot \mathrm{L}^{-1}$ to $13.02 \pm 1.62 \mu \mathrm{mol} \cdot \mathrm{L}^{-1}, p<0.05$ ), malondialdehyde (ranging from $2.16 \pm 0.45 \mathrm{nmol} \cdot \mathrm{L}^{-1}$ to $3.29 \pm 0.62 \mathrm{nmol} \cdot \mathrm{L}^{-1}, p<0.05$ ) and creatine kinase (ranging from $118.14 \pm$ 18.21 U.I... ${ }^{-1}$ to $185.59 \pm 6.96$ U.I... ${ }^{-1}, p<0.05$ ). In parallel, ascorbic acid and total plasma antioxidant potential had a slight decrease during and after exercise. Considering that alterations in oxidative stress parameters associated with inadequate ingestion of nutrients can affect health and performance of game players, further studies are needed to evaluate the inclusion of an nutritional education program and extent of biochemical changes through athlete's recovery period.
\end{abstract}

Keywords: Health; Nutrition; Oxidative Stress

\section{Introduction}

Futsal is an indoor soccer (5-a-side) officially approved by FIFA (Fédération Internationale de Football Association). FIFA Futsal World Cup (2008) showed that it is practiced by over two million registered and active players (men and women) worldwide and is one of fastest increasing sports in recent times [1]. Despite of the global status there are few studies available in the scientific literature about its physiological variables.

Futsal is characterized as an intermittent sport that makes high physical, technical, and tactical demands on players [2]. Recently, studies evaluating match demands of futsal demonstrated that players spent more than $50 \%$ of the playing time at exercise intensities higher than $90 \%$ of maximum $\mathrm{HR}\left(\mathrm{HR}_{\max }\right)$ and blood lactate concentration increased after physical stimulation, reaching average values of $5.3 \mathrm{mmol} \cdot \mathrm{L}^{-1}[3,4]$. These data suggests that futsal games demands high physical effort energetically sustained mainly by anaerobic metabolism. Analy-

"Corresponding author. sis of movement demands has showed that players performed on average one sprint every $79 \mathrm{~s}$ and changes in locomotors activities every $3.28 \mathrm{~s}$ during a match $[4,5]$.

Sports with high-intensity physical activities, like futsal, can promote important metabolic alterations that may impair player's performance due to excessive production of free radicals (FR) and oxidative stress [6]. FR and correlated reactive oxygen and nitrogen species, are normally generated in cells and tissues by many processes of human metabolism [7]. However, under physiological conditions, these species are normally neutralized by the antioxidant defense system, including antioxidant vitamins, enzymes and proteins [8]. During exercise, FR production increases significantly and if the rise exceeds the cells antioxidants capacity oxidative stress can be installed, promoting lipid peroxidation and tissue damage [9]. This can lead to alterations of the structural and functional properties of the cell membrane lipid bilayer, impairing selective permeability and promoting cellular damage and leakage of substances into the extracellular environment $[7,8]$. The consequences of oxidative stress 
to physical performance include time limiting of exercise, delayed-onset muscle soreness and contraction-induced muscle injury [10]. Therefore, the evaluation of oxidative stress products and the antioxidant defense system in athletes is of great value to study strategies in the promotion of physical performance and recovery after exercise.

The physiological demands of futsal and its practitioners, especially women, are still scarce in the literature. Only a few scientific studies have been carried on futsal and most of them involving male players. Thus, the objective of this study was to evaluate the physical, physiological and nutritional characteristics of female futsal players and investigate changes in biomarkers of oxidative stress under intermittent physical activity.

\section{Methods}

\subsection{Human Volunteers}

Eight healthy, trained university women futsal players [age $21.3 \pm 3.2$ years, body mass $64.5 \pm 5.6 \mathrm{~kg}$, height $169.5 \pm 6.5 \mathrm{~cm}$, body mass index $22.45 \pm 2.25 \mathrm{~kg} / \mathrm{m}^{2}$, body fat percentage $22.8 \% \pm 2.2 \%$ according to Jackson et al. [11] and maximal oxygen uptake $\left(\mathrm{VO}_{2 \max }\right) 50.8 \pm$ $3.3 \mathrm{ml} \cdot \mathrm{kg}^{-1} \cdot \mathrm{min}^{-1}[12]$; mean $\pm \mathrm{SD}$ ] from the official futsal team of the Federal University of Rio de Janeiro (UFRJ), Brazil, participated in this research. The study was approved by the Ethics Committee of the Instituto de Estudos em Saúde Coletiva from UFRJ and participants were informed verbally and in writing before the procedures and provided their written consent.

The training routine of the futsal players included training for two hours, four times per week and competitive games in "championships" every week.

\subsection{Experimental Design and Procedures}

All participants reported to the laboratory on the day of the experimental procedures early in the morning, after 8 hours fasting, to perform the first blood sampling (before exercise-PRE) and consumed a standard breakfast adjusted according to individual recommendations [13].

The evaluation of nutrient intake was performed using the food frequency questionnaire (FFQ) [14] and dietary 24 hours recall (R24). The R24 was also applied in two other moments: 1) anthropometric assessment; and 2) measurement of $\mathrm{VO}_{2 \max }$, totaling three $\mathrm{R} 24$, which were analyzed using the software NutWin (2003, University of São Paulo). The participants were instructed to maintain their usual dietary pattern throughout the study.

The exercise training protocol was the Loughborough Intermittent Shuttle Test (LIST), according to Nicholas et al. [15], which involved periods of exercise in varied intensity (walking, sprint, and running at 55\% and 95\% $\mathrm{VO}_{2 \max }$ ), for 15 minutes alternated with 3 minutes of pas- sive recovery. The described activities were performed continuously inside a $20 \mathrm{~m}$ distance delimited by colored cones. The exercise protocol was carried out on the court where the games and training are normally conducted (temperature around $25^{\circ} \mathrm{C}$ ) and blood samples were also collected during (MID) and immediately after (POST) the LIST.

Heart rate (HR) was monitored and continuously registered every $15 \mathrm{~s}$ throughout the exercise training protocol. The HR was also evaluated during a competitive game (Copa União de Futsal), covering all volunteers in this study aiming to compare with the results obtained in the LIST.

\subsection{Blood Sampling}

Venous blood samples were collected from the antecubital vein into tubes containing heparin and an aliquot of whole blood was separated on capillaries for determination of haematocrit according Cholewa et al. [16]. The data obtained in plasma at MID and POST was corrected for haematocrit changes (hemoconcentration). The remaining blood material was immediately centrifuged at $3000 \mathrm{rpm}$ for 10 minutes to obtain the plasma. The plasma was separated into aliquots and quickly frozen at $-20^{\circ} \mathrm{C}$ for glucose, lactate and creatine kinase $(\mathrm{CK})$, and at $-80^{\circ} \mathrm{C}$ for subsequent biochemical analysis of ascorbic acid (AA), total antioxidant potential, malondialdehyde (MDA) and lipid hydroperoxides (LOOHs).

\subsection{Biochemical Assays}

Glucose, lactate and CK plasma concentration were analyzed by spectrophotometry using commercial test kits [DOLES-10231810084 (Goiás, Brazil)/K084-2 BIOCLIN-10269360143 (Minas Gerais, Brazil)/DOLES10231810072 (Goiás, Brazil), respectively]. Plasma AA was determined by reverse-phase high-performance liquid chromatography (HPLC-Shimadzu LC-2010), according to Bobrowicz et al. [17]. Samples and standards $(20 \mu \mathrm{L})$ were injected onto a $4.6 \mathrm{~mm} \times 25 \mathrm{~cm}$ chromatographic column packed with micro-Bondapak C18 (Hypersil) with the absorbance read at $248 \mathrm{~nm}$. Concentration of AA was determined by linear regression from an AA standard curve (10 - $50 \mu \mathrm{mol} /$ Supelco). Total plasma antioxidant potential was evaluated by the ferric reducing ability of plasma assay (FRAP), according to Benzie \& Strain [18]. Samples were submitted to FRAP analyses with modifications of McAnulty et al. [19], as follows: $10 \mu \mathrm{L}$ of sample and $300 \mu \mathrm{L}$ of FRAP reagents were added in a 96-well microplate and absorbance was measured at $593 \mathrm{~nm}$. The concentration of FRAP were expressed as AA equivalents determined by linear regression from an AA standard curve (90 - $720 \mu \mathrm{mol})$. Plasma MDA was determined by reverse-phase HPLC 
(Shimadzu LC-2010) according to Karatas et al. [20]. Samples and standards $(20 \mu \mathrm{L})$ were injected onto a 4.6 $\mathrm{mm} \times 25 \mathrm{~cm}$ chromatographic column packed with micro-Bondapak C18 (Hypersil) and chromatograms were monitored at $254 \mathrm{~nm}$. Concentration of MDA was determined by linear regression from a 1,1,3,3-tetraethoxypropane standard curve $(0-50 \mathrm{nmol} / \mathrm{Sigma})$. LOOHs levels were determined by the method of xylenol orange version 2 (FOX2) in accordance with Södergren et al. [21]. The FOX2 assay is coupled with the selective hydroperoxide reductant triphenylphosphine (TPP-Sigma) [22], to determine whole plasma LOOHs. LOOHs content was determined by linear regression from a hydrogen peroxide $\left(\mathrm{H}_{2} \mathrm{O}_{2}\right)$ standard curve $(5-50 \mu \mathrm{mol} / \mathrm{Merck})$.

\subsection{Statistics}

Analysis of variance (ANOVA) with repeated measures for normally distributed data was used to establish whether results of biochemical analysis during and after exercise were significantly different from baseline results. Significant main effects and interactions were further analyzed using Tukey's post hoc test. A paired sample $t$ test was used to determine differences between LIST and futsal match HR data. $p$-values below 0.05 were considered statistically significant and data were presented as means and standard deviations $(\mathrm{X} \pm \mathrm{SD})$.

\section{Results}

The dietary analysis obtained from R24 showed that the mean vitamin A $(510.9 \pm 147.0 \mu \mathrm{g}$ RE), C $(69.7 \pm 27.5$ $\mathrm{mg})$ and $\mathrm{E}(4.8 \pm 1.4 \mathrm{mg} \mathrm{TE})$ intake was below the dietary reference intake [23] (Table 1).

These data are consistent with those obtained through analysis of the FFQ, which showed that, in general, the futsal players presented a low-frequency intake of vegetables and fruits.

The energy intake of the players in this research

Table 1. Female futsal players' mean intakes of total energy, macro and micronutrients.

\begin{tabular}{cc}
\hline Variables & Intake \\
\hline Energy (kcal/day) & $2937 \pm 380$ \\
Carbohydrate (g/kg weight/day) & $5.1 \pm 1.7$ \\
Fat (g/kg weight/day) & $1.4 \pm 0.1$ \\
Protein $(\mathrm{g} / \mathrm{kg}$ weight/day) & $2.2 \pm 0.3$ \\
Vitamin A ( $\mu \mathrm{g}$ RE) & $510.9 \pm 147.0$ \\
Vitamin C (mg) & $69.7 \pm 27.5$ \\
Vitamin E $(\mathrm{mg} \mathrm{TE})$ & $4.8 \pm 1.4$
\end{tabular}

Note: Values expressed as mean \pm standard deviation. ranged from a minimum of $2494 \mathrm{kcal} /$ day to a maximum $3469 \mathrm{kcal} /$ day with a mean of $2937 \pm 380 \mathrm{kcal} /$ day. Considering the physical activity (PA) levels described in the position of the American Dietetic Association and the American College of Sports Medicine [13] the energy intake of futsal athletes ranging from "sedentary" (minimum) to "active" (maximum), respectively, with a mean to "low active" PA level. Considering a PA level ranging from "low active" to "active", because the routine of training and competitions (non professional players), the futsal players have a calculated energy requirement [13] estimated at $2770-3667 \mathrm{kcal} / \mathrm{day}$, which includes the energy intake observed in this study. Energy consumption as macronutrients was also compared to the recommendations [13]. Carbohydrate intake $(5.1 \pm 1.7 \mathrm{~g} / \mathrm{kg}$ of body weight/day) was below the lower recommended limit $(6-10 \mathrm{~g} / \mathrm{kg}$ of body weight/day) and the protein intake ( $2.2 \pm 0.3 \mathrm{~g} / \mathrm{kg}$ of body weight/day) was above the upper recommended limit $(1.2-1.7 \mathrm{~g} / \mathrm{kg}$ of body weight/ day), while the ingestion of fat $(-28.5 \%)$ was within the recommendation $(20 \%-35 \%$ of total energy intake) (Table 1).

The mean HR during the match was $174 \pm 11 \mathrm{bpm}$ and during the LIST was $167 \pm 6 \mathrm{bpm}$, which corresponds respectively to $84.3 \% \pm 2.4 \%$ and $87.8 \% \pm 3.7 .0 \%$, of the $\mathrm{HR}_{\max }$. No statistical difference was found in mean HR between the match (including 1st and 2nd halves) and the LIST. The observed HR of players was categorized in ranges and the time spent in either range was analyzed, as demonstrated in Figure 1.

Significant differences $(p<0.05)$ were found between the LIST and the futsal match, for the time spent in low HR ranges, which futsal had less periods of time in low HR ranges than the LIST.

The LIST induced a significant increase in plasma glucose content at MID when compared with PRE values $(p<0.05)$ returning to baseline at POST (Table 2), while plasma lactate increased significantly at MID values $(p<$ 0.05 ) and kept elevated at POST when compared with

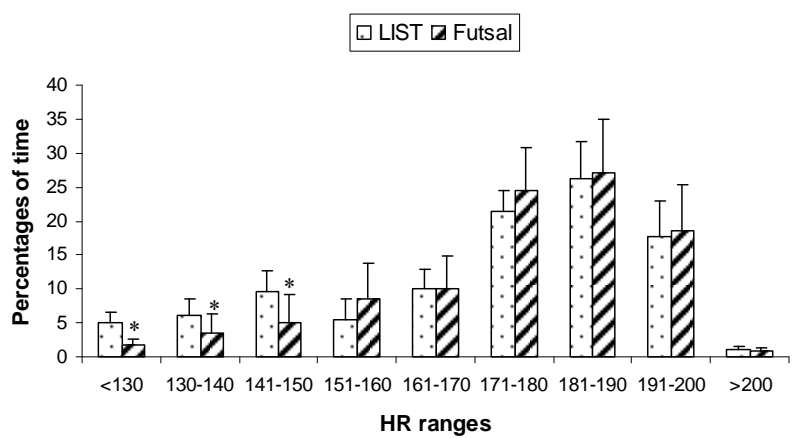

Figure 1. Percentages of time spent in different heart rate (HR) ranges during LIST and Futsal match. *: Significance difference $(p<0.05)$ with LIST values. Note: Values Expressed as mean \pm standard deviation. 
Table 2. Glucose, lactate and ascorbic acid plasmatic from the futsal players in three periods of time: pre (PRE), middle (MID) and post exercise (POST).

\begin{tabular}{cccc}
\hline & PRE & MID & POST \\
\hline $\begin{array}{c}\text { Glucose } \\
\left(\mathrm{mmol} \cdot \mathrm{L}^{-1}\right) \\
\begin{array}{c}\text { Lactate } \\
\left(\mathrm{mmol} \cdot \mathrm{L}^{-1}\right)\end{array}\end{array}$ & $4.62 \pm 0.29^{\mathrm{a}}$ & $6.24 \pm 0.84^{\mathrm{a}, \mathrm{b}}$ & $4.67 \pm 0.49^{\mathrm{a}}$ \\
$\begin{array}{c}\text { Ascorbic acid } \\
\left(\mu \mathrm{mol} \cdot \mathrm{L}^{-1}\right)\end{array}$ & $94.67 \pm 6.43$ & $92.11 \pm 4.66$ & $89.45 \pm 3.71$ \\
\hline
\end{tabular}

$\overline{a, b, c}$ Different letters in the same row indicate significantly difference $(p<$ $0.05)$. Note: Values expressed as mean \pm standard deviation.

the PRE values (Table 2). No significant differences were found in plasma AA concentration in any analyzed time point (Table 2).

Plasma total antioxidant potential (Figure 2(a)) had slight decreases at MID $\left(533.01 \pm 87.92 \mu \mathrm{mol} \cdot \mathrm{L}^{-1}\right)$ and POST $\left(456.22 \pm 85.77 \mu \mathrm{mol} \cdot \mathrm{L}^{-1}\right)$ vs PRE values $(544.05$ $\left.\pm 95.04 \mu \mathrm{mol} \cdot \mathrm{L}^{-1}\right)$ but there was no statistical significance. Plasma LOOHs (Figure 2(b)) concentration in-

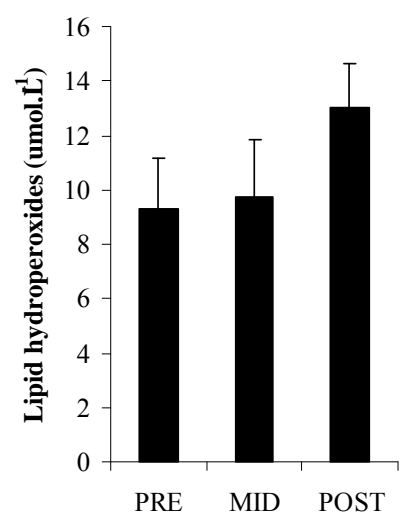

(a)

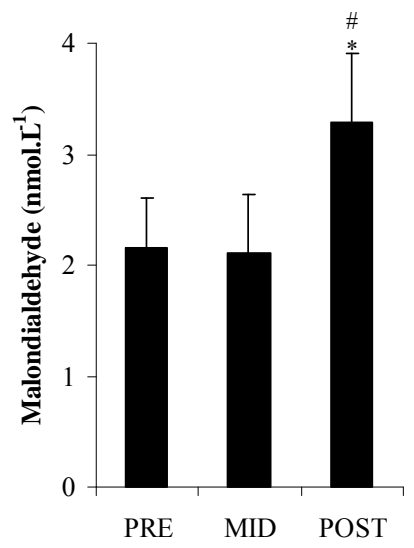

(c) creased significantly at POST $(p<0.05)(13.02 \pm 1.62$ $\left.\mu \mathrm{mol} \cdot \mathrm{L}^{-1}\right)$ vs PRE values $\left(9.32 \pm 1.86 \mu \mathrm{mol} \cdot \mathrm{L}^{-1}\right)$, while plasma MDA levels (Figure 2(c)) and CK activity (Figure 2(d)) significantly increased at POST $(p<0.05)$ $\left(3.29 \pm 0.62 \mathrm{nmol} \cdot \mathrm{L}^{-1} ; 185.59 \pm 6.96\right.$ U.I... ${ }^{-1}$, respectively) vs PRE $\left(2.16 \pm 0.45 \mathrm{nmol} \cdot \mathrm{L}^{-1} ; 118.14 \pm 18.21\right.$ U.I... ${ }^{-1}$, respectively) and MID values $(2.10 \pm 0.54$ $\mathrm{nmol} \cdot \mathrm{L}^{-1} ; 127.81 \pm 15.07$ U.I... ${ }^{-1}$, respectively).

\section{Discussion}

The present study evaluated the physical, physiological and nutritional profile of female university futsal players and the biochemical changes during and after intermittent exercise training. The assessments proposed by this research are of great utility for the scientific and professional community due to scarcity of research with futsal, especially with women.

The anthropometric and functional profile of futsal players, in this study, was similar and consistent with other university female team sport, such as soccer, and

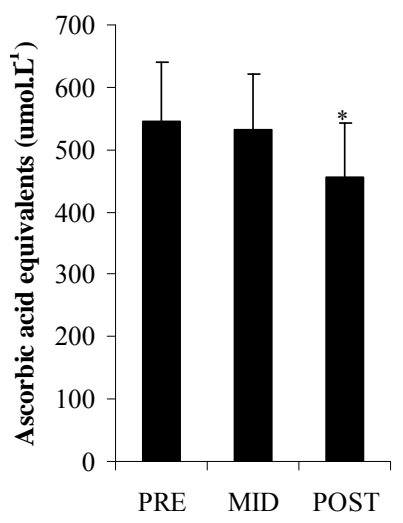

(b)

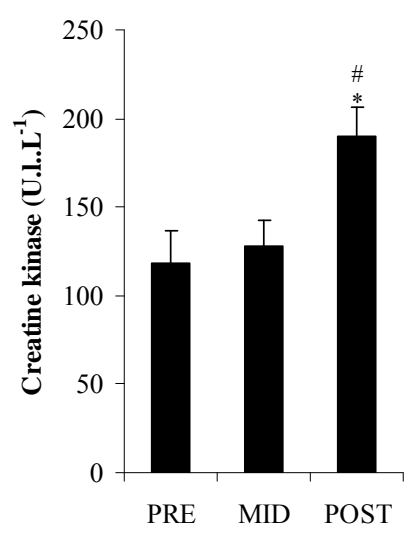

(d)

Figure 2. Total antioxidant potential as plasma ascorbic acid equivalents concentrations (a); Plasma lipid hydroperoxides concentrations (b); Plasma malondialdehyde concentrations (c); Plasma creatine kinase activity (d); in three periods of time: pre (PRE), middle (MID) and post exercise (POST). *: Significant difference $(p<0.05)$ with the PRE values; \#: Significant difference $(p<0.05)$ with the MID values. Note: Values expressed as mean \pm standard deviation. 
runners, except for $\mathrm{VO}_{2 \max }$, which is a variable parameter among sports modalities [24,25].

In general data supplied by the FFQ showed a low consumption of fruits and vegetables, which were confirmed by the analysis of R24, where the intake of nutrients present in higher amounts in those food groups, vitamins $\mathrm{A}, \mathrm{C}$ and $\mathrm{E}$, were below the dietary reference [23]. The dietary analysis obtained from R24 showed adequate energy intake according to activity level and recommendations although the distribution of energy in macronutrients (carbohydrates-CHO and proteins) was found inadequate [13] (Table 1). Clark et al. [26] worked with female soccer player from a university of the United States and found similar results as this study, where the players appeared to meet caloric needs but failed to meet minimum recommendations of $\mathrm{CHO}$ and micronutrients.

A futsal match implies several acute physiological changes, such as increased cardiac output and blood flow, due to the large variety of physical activities (e.g. sprints, intermittent running or resistance exercise). The LIST protocol has been widely used in studies that approached sports such as rugby, hockey and soccer $[15,27,28]$ as an experimental model of exercise and it presents intermittent activities (e.g. walk, sprint and running) that may correspond to the efforts of a futsal match. The match examined in the present study was a competitive game and the mean HR registered during the match $(174 \pm 11)$ were not statistically different from the LIST $(167 \pm 6)$. However, during the match the players had minor periods of time in low HR (less than $150 \mathrm{bpm}$ ) than the LIST (Figure 1). Probably, it resulted from the different match demands and position of athletes. However, a conclusion about this subject could only be done beyond a well controlled study involving different competitive games, which was not the aim of the present investigation. Here, it was demonstrated that the exercise protocol can have similar physical effort, measured as HR, of a competitive game. Carrying out exercise protocols, such as LIST in studies involving biochemical assessment is needed in order to attain the straight control of many variables that can influence metabolic response.

The exercise intensity can also be assessed by measuring blood lactate levels. In this study, after the exercise protocol, average values of lactate $5.87 \pm 1.46 \mathrm{mmol} \cdot \mathrm{l}^{-1}$ (Table 2) were similar to those obtained by Castagna et al. [4], 5.3 (1.1 to 10.4$) \mathrm{mmol} \cdot \mathrm{l}^{-1}$, with futsal players after a game-play. It can be accepted that the LIST protocol, in this study, was intense as a futsal game [4]. Lactate values normally increases after vigorous physical exercise mainly due to the high metabolic need for energy (partial production of energy through the conversion of glucose to lactate) and absence of oxygen (anaerobic metabolism) [29].

Intense exercise stimulus can induce the production of
FR which may lead to oxidative stress and cause damage to cellular tissue [6]. FR are normally neutralized by an elaborate antioxidant defense system that consists of enzymes such as catalase, superoxide dismutase, glutathione peroxidase, and numerous non-enzymatic antioxidants, including vitamins $\mathrm{A}, \mathrm{E}$ and $\mathrm{C}$, glutathione, ubiquinone, and flavonoids [8]. Nutrition provides an important part of the non-enzymatic antioxidants system; however, insufficient micronutrient supply is often reported by athletes, especially women [26,30]. Nevertheless, exercise can produce an imbalance between reactive oxygen species and antioxidants, which is referred to as oxidative stress. On the other hand, the body appears able to withstand a limited increase in FR and it may be necessary in some cases for conditioning and metabolic adaptation [31]. Thus, evaluation of biomarkers of oxidative stress in biological fluids is necessary for knowledge about the production magnitude of these substances and to approach the physical condition of athletes, their training and recovery.

In this study it was investigated the lipid peroxidation, through measurements of MDA and LOOHs, the total antioxidant potential, the plasma content of AA (component of nonenzymatic antioxidant system) and the CK as an indirect marker of muscle damage (Figures 2 (a)-(d)). The increase in plasma LOOHs, MDA and CK immediately after the end of exercise in parallel with the decrease tendency of AA and total plasma antioxidant, associated with the inadequate dietetic consumption of antioxidants vitamins (A, C and $\mathrm{E}$ ), may be considered risk factors for oxidative stress in those players. The long term insufficient intake of antioxidant nutrients, can compromise the non-enzymatic antioxidants system, which along with the antioxidant enzymes is responsible for FR scavenging in the body.

Generally, research involving analysis of biomarkers of oxidative stress has presented controversial results. As regards the total plasma antioxidant potential, for example, some studies reported results that showed increased, decreased or no significant difference in plasma concentration $[19,32,33]$. One possible reason for the observed discrepancies among studies is the different techniques employed for analysis and comparison of results.

Nevertheless, in this study, data on biomarkers of oxidative stress, in times that were analyzed (PRE, MID and POST) showed significant differences, with an acute elevation of some markers (LOOHs, MDA and CK) after exercise. The data found in literature for sports similar to futsal, such as soccer, show that MDA values after physical exercise may remain altered for up to 24 hours, whereas the plasma concentration of $\mathrm{CK}$ reaches its peak between 6 and 24 hours after physical activity [24]. Considering that those changes may continue for up to 24 hours after exercise, strategies to minimize the possible 
effects of these harmful substances in the competitive player's recovery period should be recommended. This was a preliminary study and further research involving female futsal players are required to actually establish a pattern of physiological behavior with the practice of exercise and also alternatives that could help the physical performance of this population.

\section{Conclusion}

In summary, this study was undertaken to examine the university female futsal players concerning the physical, physiological and nutritional characteristics and the biochemical changes with practice of physical activity. Futsal players reported a low intake of fruits and vegetables, being the micronutrients (vitamins $\mathrm{A}, \mathrm{C}$ and $\mathrm{E}$ ) below the recommendation. A nutritional education program should be included in the training routine of the players in order to introduce concepts of health diet that may encourage higher consumption of vitamins and minerals rich food. Exercise training (LIST) promoted a significant increase in biomarkers related to lipid peroxidation (MDA and LOOHs) and muscle damage (CK), while there was a decreasing tendency in total antioxidant potential and ascorbic acid concentration. These results, although preliminary, suggest changes in the redox capacity of the organism and indicate the need for further research aiming to assess the recovery period and verify if nutritional orientation would modify biochemical profile.

\section{Acknowledgements}

This work was supported by Fundação de Amparo à Pesquisa do Estado do Rio de Janeiro (FAPERJ) and Conselho Nacional de Desenvolvimento Científico e Tecnológico (CNPQ).

We thank the futsal players involved in the study for their committed participation and the technical assistance of Ricardo Ramos, Marcus Vinícius Ferreira and Leandro Motta, from the Federal University of Rio de Janeiro. We are grateful to Felipe Detommaso for performing the blood collection and to the students and professionals who assisted in the research, Natasha Kelber, Jéssica Socas, Andrea Ferreira, Homero Júnior and Ana Cristina Barreto.

\section{REFERENCES}

[1] FIFA, "The history of futsal," Acessed 15 October 2010. http://www.fifa.com

[2] J. C. Barbero-Álvarez, S. D’Ottavio, J. Vera and C. Castagna, "Aerobic Fitness in Futsal Players of Different Competitive Levels," Journal of Strength and Conditioning Research, Vol. 23, No. 7, 2009, pp. 2163-2166. doi:10.1519/JSC.0b013e3181b7f8ad

[3] J. C. Barbero-Álvarez, V. M. Soto, V. Barbero-Álvarez and J. Vera, "Match Analysis and Heart Rate of Futsal Players during Competition," Journal of Sports Science, Vol. 26, No. 1, 2008, pp. 63-73. doi:10.1080/02640410701287289

[4] C. Castagna, S. D’Ottavio, J. Vera and J. C. BarberoÁlvarez, "Match Demands of Professional Futsal: A Case Study," Journal of Science and Medicine in Sport, Vol. 12, No. 4, 2009, pp. 490-494. doi:10.1016/j.jsams.2008.02.001

[5] S. N. Doğramaci and M. L. Watsford, "A Comparison of Two Different Methods for Time-Motion Analysis in Team Sports," International Journal of Performance Analysis in Sport, Vol. 6, No. 1, 2006, pp. 73-83.

[6] K. J. Davies, A. T. Quintanilha, G. A. Brooks and L. Packer, "Free Radicals and Tissue Damage Produced by Exercise," Biochemical and Biophysical Research Communications, Vol. 107, No. 4, 1982, pp. 1198-1205. doi:10.1016/S0006-291X(82)80124-1

[7] M. L. Urso and P. M. Clarkson, "Oxidative Stress, Exercise, and Antioxidant Supplementation," Toxicology, Vol. 189, No. 1-2, 2003, pp. 41-54. doi:10.1016/S0300-483X(03)00151-3

[8] J. Finaud, G. Lac and E. Filaire, "Oxidative Stress: Relationship with Exercise and Training," Sports Medicine, Vol. 36, No. 4, 2006, pp. 327-358. doi:10.2165/00007256-200636040-00004

[9] C. K. Sen, "Antioxidant and Redox Regulation of Cellular Signaling: Introduction," Medicine and Science in Sports and Exercise, Vol. 33, No. 3, 2001, pp. 368-370. doi:10.1097/00005768-200103000-00005

[10] A. K. Banerjee, A. Mandal, D. Chanda and S. Chakraborti, "Oxidant, Antioxidant and Physical Exercise," Molecular and Cellular Biochemistry, Vol. 253, No. 1-2, 2003, pp. 307-312. doi:10.1023/A:1026032404105

[11] A. S. Jackson, M. L. Pollock and A. Ward, "Generalized Equations for Predicting Body Density of Women," Medicine and Science in Sports and Exercise, Vol. 12, No. 3, 1980, pp. 175-181. doi:10.1249/00005768-198023000-00009

[12] L. A. Léger and J. Lambert, "A Maximal Multistage 20-m Shuttle Run Test to Predict $\mathrm{VO}_{2 \max }$," European Journal of Applied Physiology and Occupational Physiology, Vol. 49, No. 1, 1982, pp. 1-12. doi:10.1007/BF00428958

[13] N. R. Rodriguez, N. M. DiMarco and S. Langley, "Position of the American Dietetic Association, Dietitians of Canada, and the American College of Sports Medicine: Nutrition and Athletic Performance," Journal of the American Dietetic Association, Vol. 109, No. 3, 2009, pp. 509-527. doi:10.1016/j.jada.2009.01.005

[14] V. S. Panza, E. Wazlawik, R. G. Schütz, L. Comin, K. C. Hecht and E. L. Silva, "Consumption of Green Tea Favorably Affects Oxidative Stress Markers in Weight-Trained men," Nutrition, Vol. 24, No. 5, 2008, pp. 433-442. doi:10.1016/j.nut.2008.01.009

[15] C. W. Nicholas, F. E. Nuttall and C. Williams, "The Loughborough Intermittent Shuttle Test: A Field Test That Simulates the Activity Pattern of Soccer," Journal of Sports Sciences, Vol. 18, No. 2, 2000, pp. 97-104. doi:10.1080/026404100365162 
[16] J. Cholewa, S. Poprzecki, A. Zajac and Z. Waskiewicz, "The Influence of Vitamin C on Blood Oxidative Stress Parameters in Basketball Players in Response to Maximal Exercise," Science \& Sports, Vol. 23, No. 3-4, 2008, pp. 176-182. doi:10.1016/j.scispo.2008.01.004

[17] E. Bobrowicz, J. W. Naskalski and A. Siedlecki, "Preanalytical Factors in Human Plasma Ascorbate Assay," Clinica Chimica Acta, Vol. 314, No. 1-2, 2001, pp. 237239. doi:10.1016/S0009-8981(01)00577-0

[18] I. F. Benzie and J. J. Strain, "The Ferric Reducing Ability of Plasma (FRAP) as a Measure of 'Antioxidant Power': The FRAP Assay," Analytical Biochemistry, Vol. 239, No. 1, 1996, pp. 70-76. doi:10.1006/abio.1996.0292

[19] S. R. McAnulty, L. S. McAnulty, D. C. Nieman, J. D. Morrow, L. A. Shooter, S. Holmes, C. Heward and D. A. Henson, "Effect of Alpha-Tocopherol Supplementation on Plasma Homocysteine and Oxidative Stress in Highly Trained Athletes before and after Exhaustive Exercise," The Journal of Nutritional Biochemistry, Vol. 16, No. 9, 2005, pp. 530-537. doi:10.1016/j.jnutbio.2005.02.001

[20] F. Karatas, M. Karatepe and A. Baysar, "Determination of Free Malondialdehyde in Human Serum by High-Performance Liquid Chromatography," Analytical Biochemistry, Vol. 311, No. 1, 2002, pp. 76-79. doi:10.1016/S0003-2697(02)00387-1

[21] E. Södergren, J. Nourooz-Zadeh, L. Berglund and B. Vessby, "Re-Evaluation of the Ferrous Oxidation in Xylenol Orange Assay for the Measurement of Plasma Lipid Hydroperoxides," Journal of Biochemical and Biophysical Methods, Vol. 37, No. 3, 1998, pp. 137-146. doi:10.1016/S0165-022X(98)00025-6

[22] J. Nourooz-Zadeh, J. Tajaddini-Sarmadi and S. P. Wolff, "Measurement of plasma Hydroperoxide Concentrations by the Ferrous Oxidation-Xylenol Orange Assay in Conjunction with Triphenylphosphine," Analytical Biochemistry, Vol. 220, No. 2, 1994, pp. 403-409. doi:10.1006/abio.1994.1357

[23] Food and Nutrition Board, Institute of Medicine, "DRI Dietary Reference Intakes for Vitamin C, Vitamin E, Selenium, and Carotenoids," National Academy Press, Washington DC, 2000.

[24] J. M. Sacheck, E. A. Decker and P. M. Clarkson, "The Effect of Diet on Vitamin E Intake and Oxidative Stress in Response to Acute Exercise in Female Athletes," European Journal of Applied Physiology, Vol. 83, No. 1, 2000, pp. 40-46. doi:10.1007/s004210000252

[25] S. E. Tomten and A. T, Høstmark, "Serum Vitamin E Concentration and Osmotic Fragility in Female Long-Distance Runners," Journal of Sports Sciences, Vol. 27, No. 1, 2009, pp. 69-76. doi:10.1080/02640410802448756

[26] M. Clark, D. B. Reed, S. F. Crouse and R. B. Armstrong, "Pre- and Post-Season Dietary Intake, Body Composition, and Performance Indices of NCAA Division I Female Soccer Players," International Journal of Sport Nutrition and Exercise Metabolism, Vol. 13, No. 3, 2003, pp. $303-$ 319.

[27] C. W. Nicholas, K. Tsintzas, L. Boobis and C. Williams, "Carbohydrate-Electrolyte Ingestion during Intermittent High-Intensity Running," Medicine and Science in Sports and Exercise, Vol. 31, No. 9, 1999, pp. 1280-1286. doi:10.1097/00005768-199909000-00008

[28] C. S. C. Costa, M. A. Barbosa, J. Spineti, C. M. Pedrosa and A. P. T. R. Pierucci, "Oxidative Stress Biomarkers Response to Exercise in Brazilian Junior Soccer Players," Food and Nutrition Sciences, Vol. 2, No. 5, 2011, pp. 407-413. doi:10.4236/fns.2011.25057

[29] S. Green and B. Dawson, "Measurement of Anaerobic Capacities in Humans: Definitions, Limitations and Unsolved Problems," Sports Medicine, Vol. 15, No. 5, 1993, pp. 312-327. doi:10.2165/00007256-199315050-00003

[30] M. N. Hassapidou and A. Manstrantoni, "Dietary Intakes of Elite Female Athletes in Greece," Journal of Human Nutrition and Dietetics, Vol. 14, No. 5, 2001, pp. 391-396. doi:10.1046/j.1365-277X.2001.00307.x

[31] S. Sachdev and K. J. Davies, "Production, Detection, and Adaptive Responses to Free Radicals in Exercise," Free Radical Biology and Medicine, Vol. 44, No. 2, 2008, pp. 215-223. doi:10.1016/j.freeradbiomed.2007.07.019

[32] A. Ascensão, A. Rebelo, E. Oliveira, F. Marques, L. Pereira and J. Magalhães, "Biochemical Impact of a Soccer Match-Analysis of Oxidative Stress and Muscle Damage Markers Throughout Recovery," Clinical Biochemistry, Vol. 41, No. 10-11, 2008, pp. 841-851. doi:10.1016/j.clinbiochem.2008.04.008

[33] S. Palazzetti, M. J. Richard, A. Favier and I. Margaritis, "Overloaded Training Increases Exercise-Induced Oxidative Stress and Damage," Canadian Journal of Applied Physiology, Vol. 28, No. 4, 2003, pp. 588-604. doi:10.1139/h03-045 